Vol 11, Issue 10, 2018

\title{
NEURORESTORATIVE MULBERRIES POTENTIAL OF ALZHEIMER'S DISEASE IN ANIMAL MODEL
}

\author{
FAROUK K EL-BAZ ${ }^{1}$, HANAN F ALY ${ }^{2}$, HOWAIDA I ABD-ALLA ${ }^{3 *}$, SANAA A ALI ${ }^{2}$ \\ ${ }^{1}$ Department of Plant Biochemistry, National Research Centre, 33 El Bohouth St. (former El Tahrir St.), Dokki-Giza, P.0.12622, Egypt. \\ ${ }^{2}$ Department of Therapeutic Chemistry, National Research Centre, 33 El Bohouth St. (former El Tahrir St.), Dokki-Giza, P.0.12622, \\ Egypt. ${ }^{3}$ Department of Chemistry of Natural Compounds, National Research Centre, 33 El Bohouth St. (former El Tahrir St.), Dokki-Giza, \\ P.0.12622, Egypt. Email: howaida_nrc@yahoo.com
}

Received: 07 May 2018, Revised and Accepted: 21 June 2018

\section{ABSTRACT}

Objective: Alzheimer's disease (AD) is one of the most common neurodegenerative disorders. The present study aimed to identify the potential neurorestorative of Morus alba and Morus rubra fruits extract on aluminum chloride $\left(\mathrm{AlCl}_{3}\right)$-induced $\mathrm{AD}$ rats.

Methods: Each Morus species extract M. alba and M. rubra at a dose $300 \mathrm{mg} / \mathrm{kg}$ body weight (b.wt.) was orally administered, daily for 6 weeks post $\mathrm{AlCl}_{3}$ induction $(100 \mathrm{mg} / \mathrm{kg}$ b.wt./day/6 weeks, orally). The polyphenols content was determined according to the colorimetric method of Folin-Ciocalteu using gallic acid as a standard. In addition, brain neurotransmitters, total protein content (TPC), and antioxidant biomarkers were determined. Histopathological assessment was performed on the brains of rats.

Results: Administration of $\mathrm{AlCl}_{3}$ neurotoxicity induced a significant increment of brain acetylcholinesterase, and nitric oxide, while significant decrease in four monoamines (norepinephrine, epinephrine, 5-hydroxytryptamine serotonin, and dopamin), along with brain tissue ATPase, and TPC were determined. $\mathrm{AlCl}_{3}$-induced changes in peroxidative products, such as protein carbonyl, catalase, and superoxide dismutase activity. $\mathrm{AlCl}_{3}$ induction resulted in significant decrease in antioxidant enzymes, serum level of total antioxidant capacity, and caused histological alteration for brain tissue. Treatment of AD-rats with M. alba and M. rubra (300 mg/kg b.wt./day) causes modulation of most biochemical markers brain function and confirmed by brain histopathological study.

Conclusion: Collectively, the present results indicated that M. rubra and M. alba exerts neuroprotection against $\mathrm{AlCl}_{3}$-induced brain pathology. To the best of our knowledge, none of the literature studies have demonstrated the effect of these Morus species against Al-neurotoxicity at biochemical and electron microscopic levels.

Keywords: Neurorestorative, Brain neurotransmitters, Alzheimer's disease, Morus, Polyphenols content, Histopathological assessment.

(C) 2018 The Authors. Published by Innovare Academic Sciences Pvt Ltd. This is an open access article under the CC BY license (http://creativecommons. org/licenses/by/4. 0/) DOI: http://dx.doi.org/10.22159/ajpcr.2018.v11i10.27155

\section{INTRODUCTION}

Alzheimer's disease (AD) continues to be a growing health concern worldwide as it is considered one of the most chronic neurodegenerative diseases [1]. It is characterized by progressive and slow neurodegeneration in different regions of brain [2]. Aluminum (Al) is a neurotoxin that suppresses many of the biological functions in humans and animals causing various adverse effects [3]. On exposure to $\mathrm{Al}$, the relationship between amyotrophic lateral sclerosis and dialysis encephalopathy in the neurodegenerative disorders as Alzheimer has been suggested [3]. Abnormal levels of oxidative stress have been reported in an $\mathrm{AD}$ in bloodstream and brain [1,2]. Biomarkers of oxidative stress in $\mathrm{AD}$ are classified as an oxidative attack on proteins leads to the formation of protein carbonyls (PCs) and protein nitration as well as superoxide dismutase (SOD) and lipid peroxidation [4]. On the other hand, polyphenols have gained tremendous interest as the candidates for the therapeutic and/or preventive of neurodegenerative disorders $[5,6]$. Neurodegenerative diseases are related to deficiency of antioxidants that could be prevented by radical scavengers $[7,8]$. Morus genus, a member of the Moraceae family, is a fruit that has a high content of radical scavengers including the polyphenols, prenylated flavonoids, stilbenes, and benzoic acid derivatives [5,9]. Phenolic acids and flavonols support the potential preventive health benefits of fruit-derived products' intake in relation to many diseases associated with oxidative stress [5,9]. These compounds have shown a wide range of bioactive features including neuroprotective functions and immunomodulatory activities $[6,10]$.
A major phenolic, syringic acid, isolated from M. niger have been reported to have a neuroprotective effect [11]. This effect was suggested to include the nitro-oxidative system modulation in brain and serum of mice. Zheng et al. [12] reported that flavanone $C$-glycoside, prenylated 2-arylbenzofuran derivatives (moracin glycosides), and benzoic acid derivatives were isolated from $M$. alba. These compounds showed protective influence against doxorubicin-induced cell death cardiomyopathy in H9c2 cells. The protective effect of HaCaT cells by the typical anthocyanin, cyanidin-3-O-glucoside (C3G), against ultraviolet radiation has been explained by the suppression of COX-2 expression and by the scavenging of reactive oxygen species (ROS). Regulation of hippocampal ERK expression has been demonstrated by C3G, and it also showed cognitive influence on spatial memory [13]. Furthermore, a clinical trial on the efficiency of mulberry extract in enhancing cognitive ability has been conducted [14]. A study reported an antiaging effect of herbal cream loaded with phyto extracts including M. alba [14]. Previous work showed the identification of many unsaturated fatty acids (FAs) involving omega- 3 and -6 FAs in the total extract of M. alba [5]. These acids have previously been linked to both protective and pathogenic effects in AD [15]. The metabolism of unsaturated FAs (as cis-linoleic and linolenic acids) is altered and significantly dysregulated in the brain of $\mathrm{AD}$ patient. Other acids (chlorogenic, caffeic, and syringic) were previously reported in Morus species. Phenolic acids of chlorogenic and caffeic were reported to have neuroprotective activity [16]. These properties were exerted by preventing neurodegeneration induced by oxidative 
stress in rats' brain and by inhibiting acetylcholinesterase (AChE) and butyrylcholinesterase, the key enzymes linked to AD [1,2]. Other classes of polyphenols including anthocyanins, flavanols, flavones, triterpenes, and stilbenes are found in Morus species in appropriate amount. The potential effects of compounds related to these classes in reducing cerebral injury and improving cognitive function were reported $[1,2,6]$. Morus species has been approved as effective against metabolic deteriorations and Al-induced developmental retinopathy [5,9]. None of these studies have demonstrated the effect of $M$. rubra and M. alba against Al-neurotoxicity at biochemical and electron microscopic levels. Therefore, the present search aimed to evaluate the therapeutic impact of both Morus species fruits on biochemical detritions in aluminum chloride $\left(\mathrm{AlCl}_{3}\right)$-induced $\mathrm{AD}$ rats.

\section{METHODS}

\section{Chemicals}

Donepezil, reagents, and kits were purchased from the Sigma Chemical Company (USA), whereas $\mathrm{AlCl}_{3}$ was purchased from $\mathrm{CDH}$, India.

\section{Preparation of fruits extract}

M. alba and M. rubra fruits were obtained from the local market, Egypt, during July 2017. The plant was kindly authenticated by Mrs. Treas Labib, Herbarium section, El-Orman, Egypt, with voucher specimen of 0111236,01112235 for $M$. rubra and M. alba, respectively. The fresh fruits of each species $(2.5 \mathrm{~kg}$ ) were extracted separately with $70 \%$ aqueous ethanol for $3 \mathrm{~h}$, on an orbital shaker in the dark at room temperature. Each extract was then concentrated under vacuum using rotary evaporator (Heidolph-Germany) till dryness to get 32.89 and $31.27 \%$ of crude ethanol extract of $M$. alba and $M$. rubra, respectively. The crude extracts were stored at $-4^{\circ} \mathrm{C}$ for further investigations.

\section{Determination of total polyphenols}

The total polyphenols in extracts were determined according to Folin-Ciocalteu procedure [17]. $400 \mu \mathrm{L}$ of the sample (two replicates) were taken in test tubes; $1.0 \mathrm{~mL}$ of Folin-Ciocalteu reagent (diluted 10 -fold with distilled water) and $0.8 \mathrm{~mL}$ of $7.5 \%$ sodium carbonate were added. The tubes were mixed and allowed to stand for $30 \mathrm{~min}$, and the absorption at $765 \mathrm{~nm}$ was measured against a blank, which contained $400 \mu \mathrm{L}$ of ethanol in place of sample. The total polyphenols content was expressed as gallic acid equivalent in $\mathrm{mg} / \mathrm{g}$ of ethanol extract.

\section{Biological experiment}

Animals

The male Wistar albino rats $(150 \pm 10 \mathrm{~g})$ were provided by the Animal House of the National Research Centre (NRC) and housed in group of 10 rats per cage, maintained in controlled environment condition at $26-29^{\circ} \mathrm{C}$. They were provided with a fixed light/dark cycle for 1 week $(w)$ as an adaptation period to acclimatize under normal combination with free access to water and food. The study was approved (approval no: 1456) by the Ethical Committee of the NRC, Egypt, provided that the animals will not suffer at any stage of the experiment.

\section{Induction of $\mathrm{AlCl}_{3}$ induced-AD}

$\mathrm{AlCl}_{3}$ solutions were made freshly at the beginning of each experiment. For oral administration, $\mathrm{AlCl}_{3}$ was dissolved in drinking water and administered orally in a dose of $100 \mathrm{mg} / \mathrm{kg}$, to rats daily for 6 weeks $0.5 \mathrm{~mL} / 100 \mathrm{~g}$ b.wt. [3]. Donepezil drug was daily administrated postinduction of $\mathrm{AlCl}_{3}$ for 6 weeks in a dose $10 \mathrm{mg} / \mathrm{kg}$ b.wt. parallel with berries extract [18].

\section{Experimental design}

Seventy rats were divided randomly into six groups of 10 rats each. Group 1: Normal of healthy control rats. Groups 2 and 3: M. alba and M. rubra extract-treated control rats. Group 4: serving as AD-rats, where rats were orally administered with $\mathrm{AlCl}_{3}$. Groups 5 and 6 were the AD-treated rats with ethanolic extract of $M$. alba and $M$. rubra (300 mg/kg b.wt.), daily for 6 weeks, respectively [16]. Group 7 was the AD-treated rats with standard drug $\mathrm{mg} / \mathrm{kg}$ b.wt. daily for 6 weeks.

\section{Blood samples preparation}

Overnight fasted animals were sacrificed under slight diethyl ether anesthesia. The blood was collected by puncture of the sublingual vein in clean and dry test tube. Blood was left $10 \mathrm{~min}$ to clot and centrifuged at $3000 \mathrm{rpm}$ to obtain serum. The separated serum was used for biochemical analysis of total antioxidant capacity (TAC) and PC. The other biomarkers were estimated in brain tissue.

\section{Brain tissue sampling and preparation}

At the end of the experiment, the rats were fasted overnight, subjected to anesthesia and sacrificed. The whole brain of each rat was rapidly dissected, washed with isotonic saline and dried on filter paper. The brain was weighed and homogenized in ice-cold medium containing $50 \mathrm{~m} \mathrm{MTris} / \mathrm{HCl}$ and $300 \mathrm{mM}$ sucrose at $\mathrm{pH} 7.4$ to give a $10 \%(\mathrm{w} / \mathrm{v})$ homogenate $[3,6]$. This homogenate was centrifuged at $1400 \times \mathrm{g}$ for 10 minutes at $4^{\circ} \mathrm{C}$. The supernatant was stored at $-80^{\circ} \mathrm{C}$ and used for neurotransmitters (AChE, epinephrine [Ep], norepinephrine [Nep], dopamine [DA], and 5-hydroxytryptamine [5-HT]) determination, biochemical analyses that included oxidative stress biomarker enzymatic antioxidants, ATPase, and TPC. The animals were disposed of in bags provided by the Committee of Safety and Environmental Health, NRC.

\section{Estimation of brain neurotransmitters}

Serum AChE and Ep were measured by a quantitative enzyme-linked immunosorbent assay according to the manufacturer's instructions [19]. The concentrations of brain NEp, DA, and serotonin (5-HT) were determined using high-performance liquid chromatography with electrochemical detection technique according to Zagrodzka et al. [20]. ATPase in brain was estimated according to the method of Matteucci et al. [21].

\section{Estimation of brain TPC}

TPC was estimated according to the method of Bradford [22].

\section{Estimation of antioxidant stress biomarkers}

TAC was assayed according to the method of Koracevic et al. [18]. SOD was assayed according to Nishikimi et al. [23]. CAT enzyme was determined in tissue homogenate by colorimetric assay method according to Aebi [24]. PC was determined in tissue homogenate by colorimetric assay method [24]. NO level was assayed in liver tissue by the spectrophotometric method according to Berkels et al. [25].

\section{Histological examination of brain tissue}

Histopathological assessment was performed on the brains of rats selected from each group. Brains were immediately fixed in $10 \%$ formaldehyde, embedded in paraffin, and $5 \mu \mathrm{m}$ sections were performed, then stained with hematoxylin and eosin ( $\mathrm{H}$ and $\mathrm{E})$ and examined microscopically.

\section{Statistical analysis}

All data sets were expressed as the mean \pm standard deviation (SD). The data were analyzed statistically for normal distribution using SPSS software and Co-State for Windows, version 8. Values of unshared letters are statistically significant at $\mathrm{p}<0.05$.

\section{RESULTS}

\section{Total polyphenols content}

M. rubra showed a higher level of total polyphenols as gallic acid equivalents of ethanol extract (mg/g of ethanol extract). Total polyphenols were $622.4 \pm 24.2$ and $308.4 \pm 17.6$ for $M$. alba and $M$ rubra, respectively. The data performed the average values \pm SD of three samples.

Effects of Morus species on catecholamines and AChE neurotransmitters levels

The present results declared an insignificant change in catecholamines (NEp and Ep) and AChE levels in control rats administered M. alba and M. rubra as compared to normal untreated rats. Significant reduction in NEp and Ep neurotransmitters level in AD induced rats with percentages 
$49.73 \%$ and $44.66 \%$, respectively while a significant increase in AChE $(47.52 \%)$ was recorded. On the other hand, treatment of AD rats with M. alba and M. rubra exhibited a significant increase in NEp and Ep levels compared to AD-induced rats with amelioration percentages 30.96 and $33.69 \%$, respectively, for $M$. rubra and 31.54 and $33.00 \%$, respectively, for M. alba. However, a significant reduction in AChE level was noticed with improvement percentage 78.56 and $74.26 \%$, respectively, for M. alba and M. rubra compared to anti-Alzheimer reference drug which recorded $34.18,42.98$ and $64.18 \%$, respectively (Table 1 ).

\section{Effects Morus species on monoamines neurotransmitters levels} Insignificant change was recorded in monoamines; serotonin 5-HT and DA DA levels in control rats treated with either M. alba and M. rubra as compared to control rats while there were significant reductions in 5-HT and DA levels detected in AD-induced rats by 48.74 and $50.74 \%$, respectively. Noticeable amelioration in 5-HT and DA levels on treated $\mathrm{AD}$ rats with $M$. alba and $M$. rubra with amelioration percentages 23.45 and $29.89 \%$, respectively, for $M$ rubra and 24.69 and $25.14 \%$, respectively, for $M$. alba, compared to reference drug which recorded 34.68 and $31.59 \%$, respectively (Table 2 ).

Effects Morus species on brain ATPase and total protein content (TPC) in brain tissue of AD-induced rats

Regarding ATPase and TPC (Table 3), insignificant change was recorded in control rats treated with M. alba and M. rubra compared to untreated control rats while $\mathrm{AD}$-induced rats declared significant decrease in ATPase level and TPC (TPC) by 44.44 and 58.07\%, respectively. Marked amelioration was noticed in ATPase and TPC on treated AD rats with M. alba and M. rubra with percentages 25.00 and $37.17 \%$, respectively, for $M$. alba and 33.33 and $40.80 \%$, respectively, for M. rubra compared to reference drug (36.11 and 50.93\%, respectively).

Effects of Morus species on brain NO and PC levels in brain tissue of AD-induced rats

Table 4 demonstrated an insignificant change in NO and PC levels in control rats treated with $M$. alba and M. rubra as compared to control untreated rats. Significant increase by 30.12 and $98.75 \%$, in NO and PC levels were noticed in AD-induced rats as compared to control one. Remediation of AD rats with M. alba and M. rubra showed obvious improvement in NO and PC levels with amelioration percentages 24.76 and $51.00 \%$, respectively, for $M$. rubra, while the percentages reached 28.67 and $53.25 \%$, respectively, for $M$. alba compared to standard drug which exhibited percentages of improvement by 22.26 and $80.00 \%$, respectively.

Considering antioxidant enzymes as well as TAC (Table 5), there was insignificant change in CAT enzyme activity in control rats treated with M. alba and M. rubra as compared to normal control rats while a significant increase in SOD and TAC was observed in control rats treated with either M. rubra (57.16 and 30.45\%, respectively) or M. alba (31.49 and $43.47 \%$, respectively). However, a significant decrease in SOD, CAT activities, and TAC level was detected in AD-induced rats by 52.59 , 77.77 , and $53.62 \%$, respectively. Treatment of AD rats with $M$. alba and $M$. rubra showed a significant increase in antioxidant enzyme activities and TAC by percentages of improvement $79.45,63.33$, and $84.06 \%$ of SOD, CAT, and TAC, respectively, for $M$. rubra while $M$. alba recorded $78.43,62.22$, and $69.56 \%$, respectively, compared to the reference drug which showed percentages $95.42,68.89$, and $63.77 \%$, respectively.

\section{Histological examination}

The histological examination confirms the biochemical studies. The biochemical study showed that both M. alba and M. rubra fruits did not have any side effects when given to control groups. The cerebellum of the control rats has shown granular and Purkinje layers. Moreover, Purkinje cells were observed in the Purkinje layer and large numbers of closely packed small cells in the granular layer (Fig. 1a and b). Group administered with $\mathrm{AlCl}_{3}$ revealed focal gliosis in the cerebral cortex and pyramidal cells in the hippocampus, separated from each other, with irregular outline-enlarged pyramidal cells, binucleated nuclei, vacuolation, necrosis, and aggregation of blood cells with marked distortion in granular cell layer (Fig. 1c and d). Groups had given M. alba showed the cerebellum with normal histopathological features. In the Purkinje cell layer, there were large Purkinje cells. In the granular layer, there were closely packed good-defined granular small cells (Fig. 1e and f]. Group treated with $M$. rubra was characterized by defined molecular and granular Purkinje layers (Fig. 1g and h). The histopathological characters of the cerebellum in the group given the standard drug were in the normal case of well-defined molecular and granular layers (Fig.1i and j).

\section{DISCUSSION}

The present results clearly indicated a significant rise in oxidative stress biomarkers as NO levels associated with significant decrease in antioxidant enzymes; SOD, CAT activities, as well as TAC [22]. The

Table 1: Effect of Morus species on NEp, Ep, and AChE neurotransmitters levels in brain tissue of AD-induced rats

\begin{tabular}{|c|c|c|c|}
\hline \multirow[t]{2}{*}{ Group } & \multicolumn{3}{|l|}{ Biomarker } \\
\hline & NEp (ng/g tissue) & Ep (ng/g tissue) & $\operatorname{AChE}(\mathrm{ng} / \mathrm{mL})$ \\
\hline Normal control & $190.95 \pm 10.10^{\mathrm{b}}$ & $300.12 \pm 5.10^{\mathrm{e}}$ & $90.22 \pm 2.10^{\mathrm{b}}$ \\
\hline M. alba+Control & $199.90 \pm 8.20^{\mathrm{b}}$ & $293.65 \pm 5.10^{\mathrm{e}}$ & $88.20 \pm 2.10^{\mathrm{b}}$ \\
\hline$\%$ change & +4.69 & -2.16 & 2.24 \\
\hline$\%$ of improvement & - & - & - \\
\hline M. rubra+Control & $199.61 \pm 21.10^{\mathrm{b}}$ & $295.55 \pm 6.20^{\mathrm{e}}$ & $80.10 \pm 3.10^{\mathrm{b}}$ \\
\hline$\%$ of improvement & - & - & - \\
\hline AD induced rats & $95.99 \pm 5.90^{\mathrm{a}}$ & $66.10 \pm 10.50^{g}$ & $133.10 \pm 10.1^{\mathrm{h}}$ \\
\hline$\%$ change & -49.73 & -44.66 & +47.52 \\
\hline$\%$ of improvement & - & - & - \\
\hline M. alba+AD rats & $156.22 \pm 8.90^{c}$ & $265.10 \pm 5.90^{\mathrm{g}}$ & $62.22 \pm 5.99^{\mathrm{e}}$ \\
\hline$\%$ change & -18.19 & -11.66 & -31.04 \\
\hline$\%$ of improvement & 31.54 & 33.00 & 78.56 \\
\hline M. rubra+AD rats & $155.10 \pm 7.10^{\mathrm{c}}$ & $267.20 \pm 11.90^{\mathrm{g}}$ & $66.10 \pm 2.11^{\mathrm{e}}$ \\
\hline Reference drug+AD rats & $161.25 \pm 12.90^{c}$ & $295.10 \pm 7.25^{\mathrm{e}}$ & $75.20 \pm 10.10^{\mathrm{f}}$ \\
\hline$\%$ change & -15.55 & -1.67 & -16.65 \\
\hline$\%$ of improvement & 34.18 & 42.98 & 64.18 \\
\hline
\end{tabular}

NEp: Norepinephrine, Ep: Epinephrine, AChE: Acetylcholinesterase, SD: Standard deviation, AD: Alzheimer's disease, M. alba: Morus alba, M. rubra: Morus rubra. All data were expressed as mean \pm SD of 10 rats in each group. Statistical analysis is carried out using SPSS computer program (version 8) combined with Co-state computer program, where unshared letters are significant at $\mathrm{p} \leq 0.05$ 
Table 2: Effects Morus species on 5-HT and DA neurotransmitters levels in brain tissue of AD-induced rats

\begin{tabular}{lll}
\hline Group & \multicolumn{2}{l}{ Biomarker } \\
\cline { 2 - 3 } & 5-HT (ng/g tissue) & DA (ng/g tissue) \\
\hline Normal control & $88.20 \pm 1.59^{\mathrm{a}}$ & $62.10 \pm 2.10^{\mathrm{ef}}$ \\
M. alba+Control & $87.20 \pm 5.20^{\mathrm{a}}$ & $65.10 \pm 6.10^{\mathrm{e}}$ \\
\% change & -1.13 & +4.83 \\
M. rubra+Control & $89.10 \pm 2.10^{\mathrm{a}}$ & $63.20 \pm 7.20^{\mathrm{e}}$ \\
\% change & +1.02 & +1.77 \\
AD induced rats & $45.21 \pm 2.90^{\mathrm{b}}$ & $30.59 \pm 1.90$ \\
\% change & -48.74 & -50.74 \\
M. alba+AD rats & $66.99 \pm 0.95^{\mathrm{g}}$ & $46.20 \pm 3.20^{\mathrm{c}}$ \\
\% change & -24.05 & -25.60 \\
\% of improvement & 24.69 & 25.14 \\
M. rubra+AD rats & $65.89 \pm 0.55^{\mathrm{g}}$ & $49.15 \pm 2.90^{\mathrm{b}}$ \\
\% change & -25.29 & -20.85 \\
\% of improvement & 23.45 & 29.89 \\
Reference Drug+AD rats & $75.80 \pm 6.20^{\mathrm{f}}$ & $50.20 \pm 3.10^{\mathrm{b}}$ \\
\% change & -14.06 & -19.16 \\
\% of improvement & 34.68 & 31.59 \\
\hline 5- & & \\
\hline
\end{tabular}

5-HT: 5-Hydroxytryptamine (serotonin), DA: Dopamine, AD: Alzheimer's disease, SD: Standard deviation, M. alba: Morus alba, M. rubra: Morus rubra. Mean \pm SD of 10 rats in each group. Statistical analysis is carried out using SPSS computer program (version 8) combined with Costate computer program, where unshared letters are significant at $\mathrm{p} \leq 0.05$

Table 3: Effects Morus species on brain ATPase and TPC in brain tissue of AD-induced rats

\begin{tabular}{|c|c|c|}
\hline \multirow[t]{2}{*}{ Group } & \multicolumn{2}{|l|}{ Biomarker } \\
\hline & $\begin{array}{l}\text { ATPase } \\
\text { ( } \mu \text { moles/g tissue) }\end{array}$ & $\begin{array}{l}\text { TPC } \\
\text { (mg/g tissue) }\end{array}$ \\
\hline Normal control & $9.00 \pm 0.69^{a}$ & $82.10 \pm 3.90^{\mathrm{b}}$ \\
\hline M. alba + Control & $8.59 \pm 0.62^{\mathrm{ab}}$ & $80.10 \pm 6.90^{\mathrm{b}}$ \\
\hline$\%$ change & -4.55 & -1.66 \\
\hline M. rubra + Control & $8.99 \pm 0.50^{\mathrm{ab}}$ & $81.23 \pm 5.60^{\mathrm{b}}$ \\
\hline$\%$ change & -0.1 & -2.75 \\
\hline AD induced rats & $5.00 \pm 0.39^{c}$ & $33.50 \pm 4.60^{c}$ \\
\hline$\%$ change & -44.44 & -58.07 \\
\hline M. alba + AD rats & $7.25 \pm 0.69^{c}$ & $63.20 \pm 3.25^{\mathrm{d}}$ \\
\hline$\%$ change & -19.44 & -20.90 \\
\hline$\%$ improvement & 25.00 & 37.17 \\
\hline M. rubra + AD rats & $8.00 \pm 0.55^{\mathrm{ab}}$ & $66.10 \pm 5.20^{\mathrm{d}}$ \\
\hline$\%$ change & -11.11 & -19.49 \\
\hline$\%$ improvement & 33.33 & 40.80 \\
\hline Reference Drug + AD rats & $8.25 \pm 0.53^{\mathrm{ab}}$ & $74.20 \pm 6.10^{\mathrm{e}}$ \\
\hline$\%$ change & -8.33 & -7.13 \\
\hline$\%$ improvement & 36.11 & 50.93 \\
\hline
\end{tabular}

TPC: Total protein content, AD: Alzheimer's disease, SD: Standard deviation, M. alba: Morus alba, M. rubra: Morus rubra. All data were expressed as mean \pm SD of 10 rats in each group. Statistical analysis is carried out using SPSS computer program (version 8) combined with Co-state computer program, where unshared letters are significant at $\mathrm{p} \leq 0.05$

reported value of plasma/serum and erythrocytes red blood cells levels in the AD were varied from some studies to another $[4,26,27]$. The level of SOD is enhanced by oxidative stress in early stages of AD and the brain SOD and CAT, the first line defense antioxidants were inhibited after oral administration of Al sulfate [11].

Nitrated protein and PCs were produced as a result of protein peroxidation, and oxidation has been suggested as the biomarkers of freeradical damage against protein [4,27]. High PCs level in serum/plasma of $\mathrm{AD}$ was demonstrated as the marker of oxidative stress in the brain, and it is capable of destroying neurons [4,27]. The present results declared that a significant increase in $\mathrm{PC}$ tissue of $\mathrm{AD}$-induced rats. $\mathrm{PC}$ level in cerebrospinal fluid is universally significantly higher in the AD than in controls and in other brain regions and hippocampus $[4,6]$.
Table 4: Effects of Morus species on brain NO and PC level in brain tissue of $\mathrm{AD}$-induced rats

\begin{tabular}{lll}
\hline Group & \multicolumn{2}{l}{ Biomarker } \\
\cline { 2 - 3 } & $\begin{array}{l}\text { NO } \\
\text { (U mol/g tissue) }\end{array}$ & $\begin{array}{l}\text { PC } \\
\text { (nmol/mg protein) }\end{array}$ \\
\hline Control & $76.20 \pm 9.10^{\mathrm{a}}$ & $4.00 \pm 0.10^{\mathrm{e}}$ \\
M. alba+Control & $72.90 \pm 1.20^{\mathrm{a}}$ & $3.95 \pm 0.11^{\mathrm{e}}$ \\
\% change & -4.33 & -1.25 \\
\% improvement & - & - \\
M. rubra+Control & $73.10 \pm 2.90^{\mathrm{a}}$ & $3.90 \pm 0.20^{\mathrm{e}}$ \\
\% change & -4.00 & -2.5 \\
\% improvement & - & - \\
AD induced rats & $99.10 \pm 2.90^{\mathrm{b}}$ & $7.95 \pm 1.20^{\mathrm{b}}$ \\
\% change & +30.12 & 98.75 \\
\% improvement & - & - \\
M. alba+AD rats & $77.25 \pm 0.10^{\mathrm{c}}$ & $5.82 \pm 0.03^{\mathrm{c}}$ \\
\% change & +1.38 & +45.50 \\
\% improvement & 28.67 & 53.25 \\
M. rubra+AD rats & $80.23 \pm 5.10^{\mathrm{c}}$ & $5.91 \pm 2.10^{\mathrm{c}}$ \\
\% change & +5.38 & +47.75 \\
\% improvement & 24.76 & 51.00 \\
Reference drug+AD rats & $82.19 \pm 6.13^{\mathrm{d}}$ & $4.75 \pm 0.66^{\mathrm{d}}$ \\
\% change & +7.86 & +18.75 \\
\% improvement & 22.26 & 80.00 \\
\hline N0: Nitricoxide, PC: Proten & &
\end{tabular}

NO: Nitric oxide, PC: Protein carbonyl, AD: Alzheimer's disease, SD: Standard deviation, M. alba: Morus alba, M. rubra: Morus rubra. All data were expressed as mean $\pm S D$ of 10 rats in each group. Statistical analysis is carried out using SPSS computer program (version 8) combined with Costate computer program, where unshared letters are significant at $\mathrm{p} \leq 0.05$
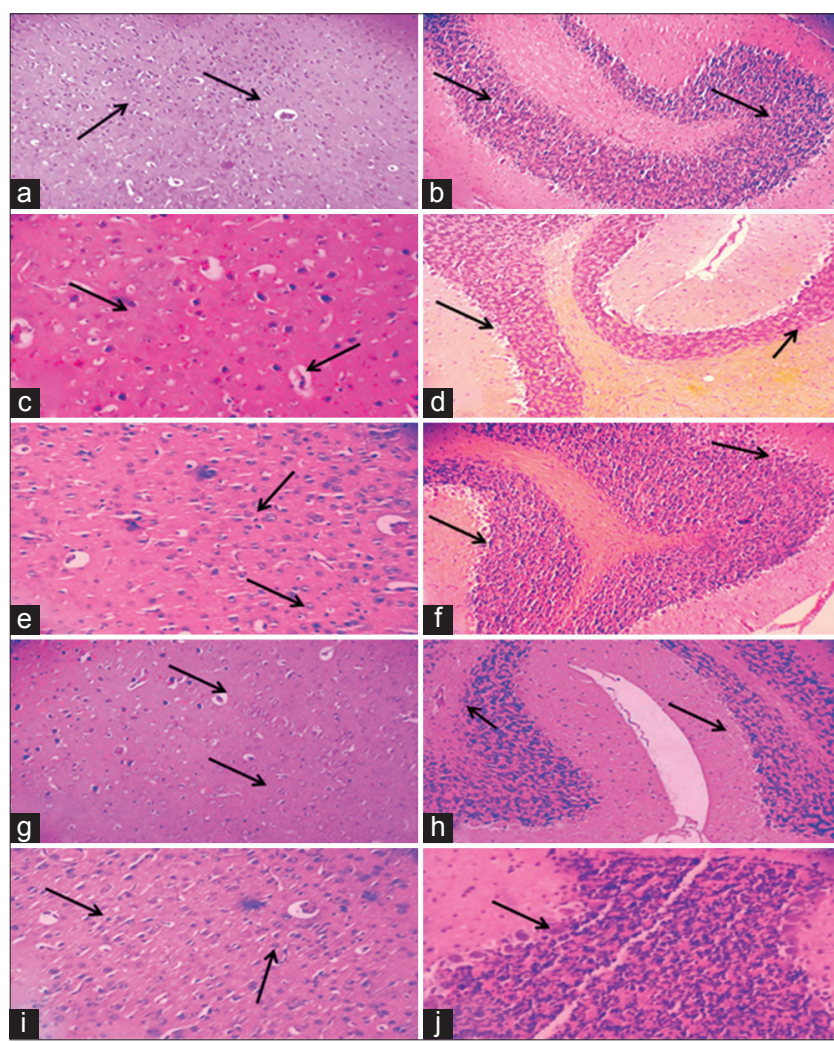

Fig. 1: ( $a$ and b) Purkinje layer and granular layer; (c and d) group administered aluminum chloride; ( $e$ and $f$ ) groups treated with Morus alba; (g and h) group treated with Morus rubra; and (i and $j$ ) group treated with the standard drug

Decreased levels of AChE activity and gamma-aminobutyric acid concentrations have been observed with senile plaques in brains of Alzheimer's. Administration of $\mathrm{AlCl}_{3}$ caused histological aberrations, elevated activity of AChE while the reduction in NEp, Ep, DA, and 5-HT 
Table 5: Effects of Morus species on brain antioxidant enzymes, SOD, and CAT activities as well as serum TAC of AD-induced rats

\begin{tabular}{|c|c|c|c|}
\hline \multirow[t]{2}{*}{ Group } & \multicolumn{3}{|l|}{ Biomarker } \\
\hline & SOD (U/g tissue) & CAT (U/g tissue) & TAC (mmol/mg protein) \\
\hline Control & $63.50 \pm 11.20^{c}$ & $0.90 \pm 0.11^{b}$ & $0.69 \pm 0.01^{\mathrm{a}}$ \\
\hline$\%$ change & +31.49 & +11.11 & +43.47 \\
\hline$\%$ improvement & - & - & - \\
\hline M. rubra+Control & $99.80 \pm 13.10^{\mathrm{ab}}$ & $0.99 \pm 0.13^{b}$ & $0.90 \pm 0.13^{b}$ \\
\hline$\%$ change & +57.16 & +10.00 & +30.45 \\
\hline$\%$ improvement & - & - & - \\
\hline AD-induced rats & $30.10 \pm 1.50^{\mathrm{d}}$ & $0.20 \pm 0.01^{\mathrm{d}}$ & $0.32 \pm 0.01^{\mathrm{e}}$ \\
\hline$\%$ change & -52.59 & -77.77 & -53.62 \\
\hline$\%$ improvement & - & - & - \\
\hline M. alba+AD rats & $79.90 \pm 15.10^{\mathrm{e}}$ & $0.76 \pm 0.11^{\mathrm{e}}$ & $0.80 \pm 0.03^{d}$ \\
\hline$\%$ change & +25.83 & -15.55 & +15.94 \\
\hline$\%$ improvement & 78.43 & 62.22 & 69.56 \\
\hline M. rubra+AD rats & $80.55 \pm 13.10^{\mathrm{e}}$ & $0.77 \pm 0.20^{\mathrm{e}}$ & $0.90 \pm 0.05^{b}$ \\
\hline$\%$ change & +26.85 & -14.44 & +30.43 \\
\hline Reference Drug+AD rats & $90.69 \pm 9.60^{\mathrm{ab}}$ & $0.82 \pm 0.11^{\mathrm{b}}$ & $0.76 \pm 0.04^{\mathrm{d}}$ \\
\hline$\%$ change & +42.82 & -8.89 & 10.14 \\
\hline$\%$ improvement & 95.42 & 68.89 & 63.77 \\
\hline
\end{tabular}

SOD: Superoxide dismutase, CAT: Catalase, TAC: Total antioxidant capacity, AD: Alzheimer's disease, SD: Standard deviation, M. alba: Morus alba, M. rubra: Morus rubra. All data are expressed as mean \pm SD of 10 rats in each group. Statistical analysis is carried out using SPSS computer program (version 8) combined with Costate computer program, where unshared letters are significant at $\mathrm{P} \leq 0.05$

in $\mathrm{AD}$ induced rats was detected. $\mathrm{AD}$ is involved the deficiency of the neurotransmitters AChE and DA that are linked to malfunctions in the catecholaminergic and cholinergic systems. Memory and cognitive function are affected by the acetylcholine-containing neurons. In the current study, the Alzheimer' group recorded low DA, NEp, and 5-HT than those of controls. In the previous study, the level of NEp is depressed in the cortex and cerebellum of animals has administered low copper or high Al [11]. The neuroprotective effect of Morus species, especially the M. rubra, may be exerted by reducing intracellular ROS level and protection of neuronal cells against oxidative injury, the most important neurodegeneration features [28,29].

In our present study, the neuroprotective activities of the investigated Morus species fruits may be related to polyphenols. Morus' polyphenols represent a diverse group of compounds such as hydroxyl cinnamates, catechins, flavonols, flavanols, stilbenoids, and tannins. Tannins are divided into hydrolyzable and condensed (proanthocyanidins) tannins. A proanthocyanidins-standardized cranberry extract was reported to alleviate $\beta$-amyloid peptide toxicity in Caenorhabditis elegans model of $\mathrm{AD}$ by improving proteostasis through heat shock transcription factor-1 [30]. Oligomeric condensed tannins (proanthocyanidins), naturally occurring antioxidants, are widely available in Morus species. An oligomeric proanthocyanidin isolated from grape seeds has been provided as antiradical scavenging agent exerts protection against DNA damage and lipid peroxidation [31]. In our current study, other Morus' polyphenols such as flavonoids (quercetin derivatives and kaempferol derivatives), phenolic acids (hydroxybenzoic and hydroxycinnamic acids) may exert the healing potency on neurotoxicity $[1,4,6]$.

In $\mathrm{AD}$ group, the antioxidant enzymes such as SOD and CAT are decreased in their activities by oxidative stress as declared in the current results $[4,32]$. In our present study, the presence of polyphenols in M. rubra and M. alba with AChE inhibiting, antioxidant properties and/ or their effect on neuronal signal transduction and neuroinflammation may be attributed to the current reported data of the extract-treated group compared with the control $[7,32,33]$.

Other essential micronutrients of trace elements and vitamins such as carotenoid $(A)$, riboflavin $\left(B_{2}\right)$, niacin $\left(B_{3}\right)$, ascorbic acid $(C)$, and tocopherol (E) were reported in high amount in the colored mulberries as purple M. rubra fruits [4,5]. Micronutrients have attracted increasing attention as potential agents for neuroprotection as many of them have antioxidant properties $[4,33]$. These compounds and fruit colorants (anthocyanins and carotenoids) play a central part in optimizing health and in the maintenance of tissue function through the interaction of hydroxyl group of anthraquinones with the active site residues of $\beta$-site amyloid precursor protein cleaving enzyme 1 [34]. Certain anthocyanins-enriched extract was reported to alleviate behavioral abnormalities of AD in the mouse model [13,35]. C3G was the major anthocyanin in many species of Morus. It has reported as an antioxidant agent and showed a protective role against vascular failure induced by peroxynitrite and endothelial dysfunction [13]. Thus, C3G may be involved in the neuroprotective effect of M. alba extract. A benzenoid (Z)-1-hydroxy-4-(2-nitrophenyl) benzene, isolated and characterized from the root bark of M. australis was reported to display inhibitory effects on adenosine diphosphate (ADP)-aggregating factor and inhibited production of NO in murine cell line [28].

The current findings demonstrated that administration of M. rubra $(300 \mathrm{mg} / \mathrm{kg})$ to rats displayed brain selective AChE inhibition. They also increase DA level, serotonin (5-HT) and NEp and prevented the metabolism of DA and 5-HT.

The role of essential FAs for the function and the integrity of nervous cell membranes and brain are well established. Mulberry fruit has essential FAs which humans cannot synthesize and must be obtained through diet. Essential FAs are polyunsaturated FAs (UFAs) with long-chain derived from a linoleic, linolenic, and oleic acid, where they are important for the formation of healthy cell membranes, the development and function of the nervous system and brain $[4,5]$. A previous work showed the GCMS of organic extracts of the M. rubra fruits established their unique constituents including unsaturated FAs [5]. UFAs including omega-3 and -6 FAs have previously been attributed to the protective activity against cell damage of the brain at various ages and during aging [15]. El-Baz et al. [5] reported the identification of a phenanthrene derivative (10-methoxy-9-phenyl-phenanthrene) in the crude alcohol extract and methylene chloride fraction of M. alba. These derivatives were reported as important pharmacological agents with diverse biological effects including NO production inhibition, radical-scavenging, and protective effect on cerebral ischemic stroke [36].

The noticeable amelioration in monoamines; 5-HT, DA, as well as NEp, which is detected on treated $\mathrm{AD}$-induced rats with M. alba, may be explained, M. alba fruits extract is considered a potent protector against 
glyphosate-induced toxicity and has protected the hippocampal neurons against amyloid $\beta$-peptide (1-42)-induced cell death in a concentrationdependent manner. Its protective effect could result from synergism or antagonism between the various bioactive polyphenols in the fruits extract [36]. These fruits extracts have a potent neuroprotective profile and also have a modulatory effect on cellular and biomolecular processes in preventing redox status to arrest apoptotic and necrotic processes underlying focal cerebral ischemia [4,5]. Polyphenols, including flavonoids as isoprenylated flavonoids (morustralins $\mathrm{A}$ and $\mathrm{B}$ ), and a prenylated flavanone, named morflavanone A were isolated from M. alba. Quercetin, kaempferol-3-rutinoside, and rutin have been isolated from many Morus species. Modulation of P-glycoprotein, rather than anti-inflammatory and antioxidant affects of Morus species could be the suggested the mechanism of polyphenols in the protection of neurons and prevention of AD [33]. Many of these compounds may cross the blood-brain barrier [33], as indicated in the present histopathological amelioration of brain tissue (E-H) as compared to standard drug (I and J).

Chronic neuroinflammation may contribute to the neuroanatomy of the pathology or the appearance of activated microglia [33]. This is ascertained in the present histopathological examination (Photomicrographs C and D), which revealed focal gliosis in the cerebral cortex and pyramidal cells in the hippocampus marked distortion in the granular cell layer. Photomicrograph 1 showed the examination of brain sections of control rats with the normal structure of the cerebral cortex (A) and hippocampus (B) (H and E, $\times 200)$. Group administered with $\mathrm{AlCl}_{3}$ revealed focal gliosis in the cerebral cortex (C), and pyramidal cells in the hippocampus marked distortion in granular cell layer (D) $(\mathrm{H}$ and E, $\times 200$ ). Group treated with $M$. alba showed the cerebellum having well-defined molecular, granular, large Purkinje cell in the Purkinje cell layer $(\mathrm{E}$ and $\mathrm{F})(\mathrm{H}$ and $\mathrm{E}, \times 200)$. Furthermore, group treated with M. rubra showed marked defined molecular, granular, Purkinje layers ( $G$ and $H$ ) ( $H$ and $E, \times 200)$. The cerebellum of the group received the standard drug showed well-defined molecular and granular layers and other normal histopathological features (I and J) (H and E, ×200).

\section{CONCLUSION}

It could be concluded that Morus can effectively protect against $\mathrm{AlCl}_{3}$-induced neurotoxicity and the mechanisms underlying the neuroprotective effect are potentially associated with its antioxidant, anti-inflammatory, and antiapoptotic properties. Both Morus species significantly improved $\mathrm{AlCl}_{3}$-induced biochemical and neurochemical abnormalities, reversed the abnormal alterations of neurotransmitters in the striatum, and alleviated oxidative stress.

\section{AUTHOR'S CONTRIBUTIONS}

Farouk K. El-Baz: Plan of work, writing and revision. Hanan F. Aly: Biochemical measurements, statistical analysis, and writing. Howaida I. Abd-Alla: Samples, biochemical measurements discussion, and corresponding author. Sanaa A. Ali: Histological investigation.

\section{CONFLICTS OF INTEREST}

Authors declare that they have no conflicts of interest.

\section{REFERENCES}

1. Jiang Y, Gao H, Turdu G. Traditional Chinese medicinal herbs as potential AChE inhibitors for anti-Alzheimer's disease: A review. Bioorg Chem 2017;75:50-61.

2. Yang Y, Wang JZ. Nature of tau-associated neurodegeneration and the molecular mechanisms. J Alzheimer's Dis 2018;62:1305-17.

3. Kawahara M, Kato-Negishi M. Link between aluminum and the pathogenesis of Alzheimer's disease: The integration of the aluminum and amyloid cascade hypotheses. Int J Alzheimers Dis 2011;2011:1-17.

4. Chang YT, Chang WN, Tsai NW, Huang CC, Kung CT, Su YJ, et al. The roles of biomarkers of oxidative stress and antioxidant in Alzheimer's disease: A systematic review. Bio Med Res Int 2014;2014:1-14.

5. El-Baz FK, Hassan AZ, Abd-Alla HI, Aly HF, Mahmoud K.
Phytochemical analysis, assessment of ant proliferative and free radical scavenging activity of Morus alba and Morus rubra fruits. Asian J Pharm Clin Res 2017;10:189-99.

6. Awad HM, Abd-Alla HI, Ibrahim MA, El-Sawy ER, Abd-Alla MM. Flavones from heavenly blue as modulators of alzheimer's amyloidbeta peptide $(A \beta)$ production. Med Chem Res 2018;27:768-76.

7. Awad HM, Abd-Alla HI, Mahmoud KH, El-Toumy SA. In vitro antinitrosative, antioxidant, and cytotoxicity activities of plant flavonoids: A comparative study. Med Chem Res 2014;23:3298-307.

8. Mohamed NZ, Abd-Alla HI, Aly HF, Mantawy M, Ibrahim N, Hassan SA. CCl4-induced hepatonephrotoxicity: Protective effect of nutraceuticals on inflammatory factors and ant oxidative status in rat. J Appl Pharm Sci 2016;4:87-100.

9. El-Baz FK, Aly HF, Abd-Alla HI. Berries supplementation modulates body weight and metabolic deteriorations in obese rats. Asian J Pharm Clin Res 2018;11:322-8.

10. Abd-Alla HI, Sweelam HM, Mohamed TA, Gabr MM, El-Safty MM, Hegazy MF. Efficacy of extracts and iridoid glucosides from Pentas lanceolata on humoral and cell-mediated immune response of viral vaccine. Med Chem Res 2017;26:2196-204.

11. Phukan P, Bawari M, Sengupta M. Promising neuroprotective plants from north-east India. Int J Pharm Pharm Sci 2015;7:28-39.

12. Zheng XK, Cao YG, Ke YY, Zhang YL, Li F, Gong JH, et al. Phenolic constituents from the root bark of Morus alba L. and their cardioprotective activity in vitro. Phytochemistry 2017;135:128-34.

13. Tan L, Yang HP, Pang W, Lu H, Hu YD, Li J, et al. Cyanidin-3-Ogalactoside and blueberry extracts supplementation improves spatial memory and regulates hippocampal ERK expression in senescenceaccelerated mice. Biomed Environ Sci 2014;27:186-96.

14. Chan EW, Lye PY, Wong SK. Phytochemistry, pharmacology, and clinical trials of Morus alba. Chin J Nat Med 2016;14:17-30.

15. Bourre JM. Roles of unsaturated fatty acids (especially omega-3 fatty acids) in the brain at various ages and during ageing. $J$ Nutr Health Aging 2004;8:163-74

16. Nag G, De B. Acetylcholinesterase inhibitory activity of Terminalia chebula, Terminalia bellerica and Emblica officinalis and some phenolic compounds. Int J Pharm Pharm Sci 2011;3:121-4.

17. Singleton, VL, Rossi, JA. Colorimetry of total phenolics with phosphomolybdic-phosphotungstic acid reagents. Am J Enol Viticult 1995;16:144-58.

18. Koracevic D, Koracevic G, Djordjevic V, Andrejevic S, Cosic V. Method for the measurement of antioxidant activity in human fluids. J Clin Pathol 2001;54:356-61.

19. Fernando HA, Chin HF, Ton SH, Kadir KA. Stress and its effects on glucose metabolism and $11 \beta$-HSD activities in rats fed on a combination of high-fat and high-sucrose diet with glycyrrhizic acid. Diabetes Res 2013;95:1903-13.

20. Zagrodzka J, Romaniuk A, Wieczorek M, Boguszewski P. Bicuculline administration into ventromedial hypothalamus: Effects on fear and regional brain monoamines and GABA concentrations in rats. Acta Neurobiol Exp 2000;60:333-43.

21. Matteucci E, Cocci F, Pellegrini L, Gregori G, Giampietro O. Measurement of ATPases in red cells: Setting up and validation of a highly reproducible method. Enzyme Protein 1994;48:105-19.

22. Bradford MM. A rapid and sensitive method for the quantization of microgram quantities of protein utilizing the principle of protein-dye binding. Anal Biochem 1976;72:248-54.

23. Nishikimi M, Rae NA, Yagi K. The occurrence of superoxide anion in the action of reduced phenazine methosulphate and molecular oxygen. Biochem Biophys Res Commun 1972;46:849-53.

24. Aebi H. Catalase in vitro. Methods Enzymol 1984;105:121-6.

25. Berkels R, Purol-Schnabel S, Roesen R. Measurement of nitric oxide by reconversion of nitrate/nitrite to NO. Methods Mol Biol 2004;279:1-8.

26. Padurariu M, Ciobica A, Hritcu L, Stoica B, Bild W, Stefanescu C. Changes of some oxidative stress markers in the serum of patients with mild cognitive impairment and Alzheimer's disease. Neurosci Lett 2010;469:6-10.

27. Cristalli DO, Arnal N, Marra FA, De Alaniz MJ, Marra C. Peripheral markers in neurodegenerative patients and their first-degree relatives. J Neurol Sci 2012;314:48-56

28. Liao YR, Kuo PC, Tsai WJ, Huang GJ, Lee KH, Wu TS. Bioactive chemical constituents from the root bark of Morus australis. Bioorg Med Chem Lett 2017;27:309-13.

29. Tavares L, Figueira I, McDougall GJ, Vieira HL, Stewart D, Alves PM, et al. Neuroprotective effects of digested polyphenols from wild blackberry species. Eur J Nutr 2013;52:225-36.

30. Guo H, Cao M, Zou S, Ye B, Dong Y. Cranberry extract standardized for 
proanthocyanidins alleviates $\beta$-Amyloid peptide toxicity by improving proteostasis through HSF-1 in Caenorhabditis elegans model of Alzheimer's disease. J Gerontol A Biol Sci Med Sci 2016;71:1564-73.

31. Bagchi D, Bagchi M, Stohs SJ, Das DK, Ray SD, Kuszynski CA, et al. Mitochondrial- and endoplasmic reticulum-associated oxidative stress in Alzheimer's disease: From pathogenesis to biomarkers. Int J Cell Biol 2012;2012:1-23.

32. Aly HF, Abd-Alla HI, Ali SA, Aba-Alez R, Abu-Krisha MT, Mohamed MM. Bioinformatics: Inflammatory cytokines and attenuation of diabetes hypercholesterolemia-induced renal injury using morning glory and necklace pod extracts. Asian J Pharm Clin Res 2017; 10:347-55.

33. Sawikr Y, Yarla NS, Peluso I, Kamal MA, Aliev G, Bishayee A. Neuroinflammation in alzheimer's disease: The preventive and therapeutic potential of polyphenolic nutraceuticals. Adv Protein Chem Struct Biol 2017;108:33-57.

34. Jung HA, Ali MY, Jung HJ, Jeong HO, Chung HY, Choi JS. Inhibitory activities of major anthraquinones and other constituents from Cassia obtusifolia against $\beta$-secretase and cholinesterases. J Ethnopharmacol 2016;191:152-60.

35. Vepsäläinen S, Koivisto H, Pekkarinen E, Mäkinen P, Dobson G, McDougall GJ, et al. Anthocyanin-enriched bilberry and blackcurrant extracts modulate amyloid precursor protein processing and alleviate behavioral abnormalities in the APP/PS1 mouse model of alzheimer's disease. J Nutr Biochem 2013;24:360-70.

36. Wang J, Wang T, Xie P, Yin G, Li X. New phenanthrene derivatives with nitric oxide inhibitory and radical-scavenging activities from Pholidota imbricata Hook. Nat Prod Res 2014;28:251-6. 